\title{
AMSES Becomes Materials Research Society of Japan
}

The Materials Research Society of Japan (MRS-J) is the new name adopted by the Advanced Materials Science and Engineering Society (AMSES), a member society representing Japan in the International Union of Materials Research Societies. The name was approved at the organization's annual General Assembly Meeting held December 13-14, 1990 at Kanagawa Science Park. The meeting combined society business with special events and the presentation of lectures, several symposia, and a poster session.

At the meeting, eight distinguished scientists were recognized as new honorary members of MRS-J: Prof. R.P.H. Chang, Northwestern University, United States; Dr. Min Che Chon, president, Chon International Co. Ltd., Korea; Dr. Byong Sik Jeon, standing adviser, Central Research Institute, Korea Steel Chemical Co. Ltd.,
Korea; Dr. O.C.C. Lin, president, Industrial Technology Research Institute, Taiwan, China; Dr. Kee Hyong Kim, chairman, Korea Advanced Institute of Science and Technology, Korea; Dr. M.J. Murray, Division of Materials Science and Technology, CSIRO, Australia; Prof. C.N.R. Rao, solid state and structural chemist, Indian Institute of Science, India; Dr. D.S. Yan, former vice president of Academia Sinica, Shanghai Institute of $\mathrm{Ce}$ ramics, Academia Sinica, China.

In two commemorative lectures, $\mathrm{Dr}$. Kunihiko Takeda, Asahi Chemical Co. Ltd., talked on "Uranium Condensation Technique by Ion Exchange," and Dr. Hachiro Nakanishi, Research Institute for Polymers and Textiles, spoke about the status and future of "Organic Crystals as Sensor Materials."

Three symposia focused on advanced materials, sensor materials, and structural imperfections in $\mathrm{SiO}_{2}$-based amorphous materials. Certificates were presented to several outstanding posters from among 70 poster presentations.

The 1991 MRS-J officers were introduced: Prof. Shigeyuki Sōmiya, president; Prof. Masao Doyama and Prof. Masaki Hasegawa, vice presidents; and Dr. Yoshitaka Agata, secretary and treasurer.

Future MRS-J meetings are scheduled for the following dates: Summer Meeting, July 11-12, 1991; Annual Meeting, December 12-13, 1991; Summer Meeting, July 910, 1992; Annual Meeting, December 10-11, 1992.

For more information about MRS-J and its activities, contact: MRS-J, c/o KSP, W304, 100-1 Sakato, Takatsu-ku, Kawasaki 213 Japan; phone (81) 44-819-2001; fax (81) 44-819-2009.

\section{Principal Editors of Journal of Materials Research Meet in Tokyo}

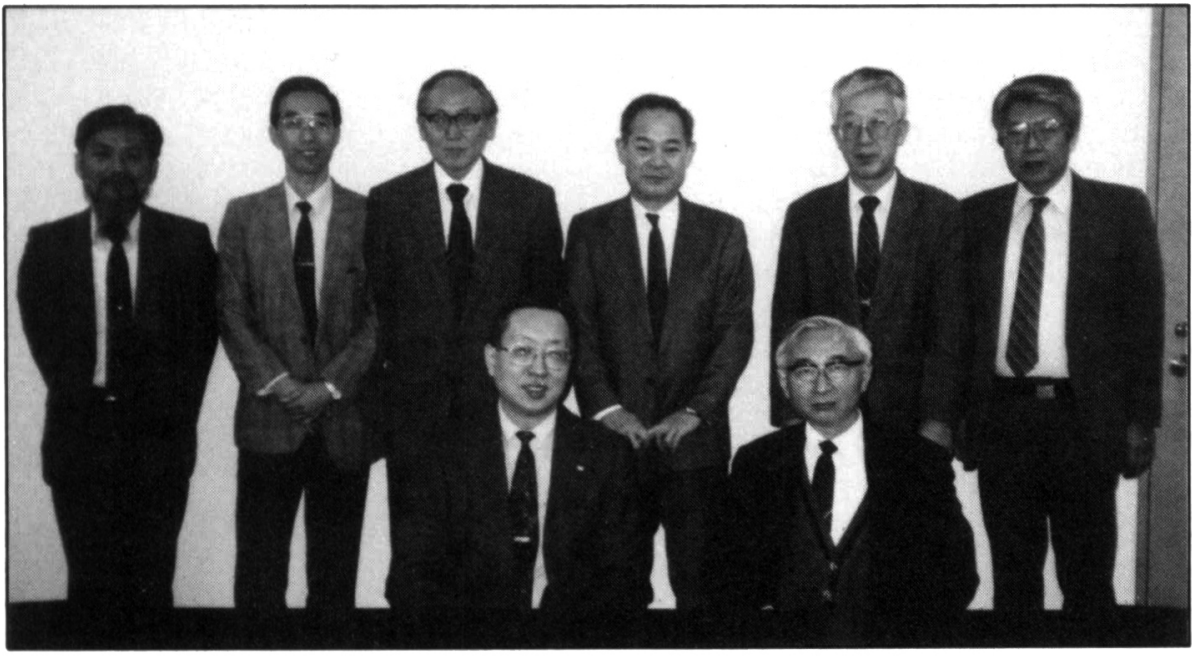

$J M R$ principal editors from Japan meet to learn about the Journal's operations.

Joumal of Materials Research principal editors from Japan met December 15, 1990 in Tokyo during the annual General Meeting of the Materials Research Society of Japan. The principal editors' meeting was held following JMR's appointment of Prof. S.
Sōmiya as Associate Editor - Japan to familiarize the newly appointed principal editors with the Journal's operations. Prof. R.P.H. Chang represented JMR Editor in Chief Walter Brown at the meeting.

For the convenience of authors in Japan and Asia, all articles submitted directly to Associate Editor Sómiya will be reviewed in Japan. After a paper is accepted in Japan, it will then be sent to the JMR Editorial Office in the United States for publication, greatly reducing the time from submission to publication. The eight principal editors in Japan are already working to assure fast, quality reviews of submitted papers. In addition, they have agreed to manage the increasing number of articles from Japan. In his report to Brown, Chang remarked, "You have a group of dynamic principal editors in Japan and they will do a fantastic job in making $J M R$ a premier materials journal in that part of the world!"

Participating in the principal editors meeting in Tokyo were Prof. Yoshihiko Moro-oka, Tokyo Institute of Technology; Dr. Keiichi Ogawa, National Research Institute for Metals; Prof. Eiichi Yasuda, Tokyo Institute of Technology; Prof. Shiushichi Kimura, Tokyo Institute of Technology; Prof. Masao Doyama, Nishi Tokyo University; and Prof. Masao Wakatsuki, University of Tsukuba. Two additional principal editors, Prof. Takashi Tokuyama, University of Tsukuba, and Prof. M. Hasegawa, University of Tokyo, were not at the meeting. 